\title{
PSYCHOSOCIAL FACTORS, ALCOHOL USE, AND HANGOVER SIGNS AMONG SOCIAL DRINKERS: A REAPPRAISAL
}

\author{
Ernest Harburg, ${ }^{1,2 *}$ Robert GunN, ${ }^{3}$ Lillian Gleiberman, ${ }^{1}$ \\ WAYNE DiFranceisco ${ }^{1}$ and ANTHONY SCHORK ${ }^{4}$ \\ ${ }^{1}$ Department of Epidemiology, School of Public Health, ${ }^{2}$ Department of Psychology, ${ }^{3}$ Department \\ of Psychiatry, Veterans Administration Hospital and ${ }^{4}$ Department of Biostatistics, School of Public \\ Health, The University of Michigan, Ann Arbor, MI 48109, U.S.A.
}

(Received in revised form 6 January 1993)

\begin{abstract}
To reappraise a prior study of hangover signs and psychosocial factors among a sample of current drinkers, we excluded a subgroup termed Sobers, who report "never" being "tipsy, high or drunk." The non-sober current drinkers then formed the sample for this report $(N=1104)$. About $23 \%$ of this group reported no hangover signs regardless of their intake level or gender, and the rest showed no sex differences for any of 8 hangover signs reported. Using multiple regression, including ethanol, age and weight, it was found that psychosocial variables contributed independently in predicting to hangover for both men and women in this order: (1) guilt about drinking; (2) neuroticism; (3) angry or (4) depressed when high/drunk and (5) negative life events. For men only, ethanol intake was also significant; for women only, being younger and reporting first being high/drunk at a relatively earlier age were also predictors of the Hangover Sign Index (HSI). These multiple predictors accounted for 5-10 times more of the hangover variance than alrohol use alone: for men, $R=0.43$, $R^{2}=19 \%$; and for women, $R=0.46, R^{2}=21 \%$. The findings suggest that hangover signs are a function of age, sex, ethanol level and psychosocial factors.
\end{abstract}

Hangover Social drinkers

\section{INTRODUCTION}

The psychosocial correlates of hangover symptoms have been little studied. The simple assumption that frequency or severity of hangover signs is due solely or largely to the amount of alcohol consumed, generally has not been questioned or tested by researchers. Yet for decades some theorists (e.g. Lolli [1], Karpman [2]) have proposed that hangover signs were "a classic illustration of psychosomatic concepts." Recently, Chafetz [3] wrote,

*All correspondence should be addressed to: Ernest Harburg, PhD., Program for Urban Health Research, 120 $1 / 2$ W. Washington Street, Ann Arbor, MI 48104, U.S.A.

\begin{abstract}
"In societies [or subcultures] that place drinking in the proper perspective and drink sensibly, there are few drinking problems and hangovers are rare. But where heavy is the name of the game, where getting drunk is $\mathbf{O . K}$., where there's conflict, ambivalence, and guilt about drinking, hangovers become pandemic. And we're involved in uptight drinking. When we're 'tense and uptight' while taking alcohol, we're more predisposed to hangover" (Chafetz, pp. 48-9)
\end{abstract}

Chafetz further asserts that alcohol may be a facilitator rather than a primary cause of hangover signs. He suggests that "stress" (induced perhaps by neuroticism, work load, marital conflict, etc.) can itself induce headache, anxiety, dizziness, tremor, nausea and so forth Under stress, even one or two drinks (or more) "will further close down the warning signs" and make the hangover more severe. 
Empirical studies of hangover signs in normal drinkers are rare. A computer search (University of Michigan Medline) of over 4000 biomedical journals from 1966 until the present yielded only 68 articles with "hangover(s)" in the title; few of these studies measured psychosocial variables. Gunn [4] reported on a sample of 42 white, male psychiatric patients at a Veterans' Administration hospital, half of whom were alcoholics and half "social drinkers." Results of this clinical survey showed that: (a) about half the men had negative attitudes toward drinking and experienced guilt during and after drinking and (b) these feelings may have played a crucial role in bringing about hangover signs. Harburg et al. [5], using data from a random sample of a small town ( $N=1266$ drinkers), found positive correlations between psychosocial factors (negative life events, neuroticism, guilt about drinking, and depression and/or anger when drunk) and frequency of hangover signs experienced when last drunk. These results prevailed at all levels of alcohol consumed, though heavier drinkers showed more severe signs.

In reappraising this study, we became convinced that the results may have been biased by a large sub-group of drinkers in the sample who claimed that regardless of the amount of alcohol they may have consumed, they "never have been high, tipsy or drunk." In the study questionnaire design, subjects answering this way were not asked about possible hangover signs, but were included in analyses as members of a "no hangover signs group." This inclusion was based on an implicit assumption that hangovers do not occur in people who claim no psychic effects from drinking. Such an assumption is not warranted. Previous research suggests that hangovers may occur whether or not a drinker notes internal changes from alcohol use while drinking [4], and hangover signs seem to have been experienced by all levels of drinkers, even by abstainers, and in the past by current nondrinkers [6].

In our sample of 1266 current drinkers, $6 \%$ of the men and $20 \%$ of the women fell into the category of drinkers who "never" get high, who are here termed "Sobers." Demographically, this subgroup was older than the remaining subjects, drank significantly less, and among the women, weighed more than women reporting getting high or drunk, and manifested several other characteristics to be reported later. Clearly, they appear to be a group with distinctive characteristics.
The present study therefore represents a complete re-analysis of the Harburg et al. [5] data. The present analysis is a refinement of method by: (1) using a scale of severity of hangover signs; (2) excluding normal Sober drinkers who "never get tipsy, high or drunk" when drinking; (3) describing the psychosocial traits and alcohol usage of these Sobers and a group of normal drinkers who report getting drunk, but had no hangover signs; (4) using multiple regression technique, and (5) testing for interaction effects. These refinements provide a closer test of the hypothesis that psychosocial factors are linked to hangover symptoms in social drinkers.

\section{METHOD \\ Sample}

The Tecumseh Community Health Study (TCHS) is a longitudinal survey of the residents of Tecumseh, Michigan, begun in 1959 (see Napier et al., [7] for a description of the project). Drinking data and psychosocial variables were collected in 1977 as part of the Family Health Project. For the 1977 data collection, a list of multi-sibling families was obtained from the 1960 TCHS census. A sample of Tecumseh families was then drawn by a random selection of "index" persons from among all the siblings in each family in the census. In addition to the index, the five-member "family sets" consisted of the spouse of the index (if married), a sibling and a first cousin both closest in age to the index person, and a randomly-selected, geneticallyunrelated person, who was matched for age and sex to the index (see Harburg et al. [8]; Moll et al. [9], for details on the family-set method). Questionnaires were sent to 2272 individuals identified by the family-set selection process, and $74 \%$ were returned $(N=1672)$ total cases. Respondents comprising each family set constitute independent random samples. Analysis of variance on any variable shows no difference among index, spouse, sibling, first cousin, and unrelated persons. Therefore, the family-set roles can be ignored in this study.

For purposes of studying the hangover signs of normal current drinkers, we first excluded non-drinkers, both past drinkers $(N=191)$ and life-long abstainers $(N=215)$. Compelling reasons also required that the Sobers who "never" get "tipsy, high or drunk" also be excluded $(N=162)$. First, as mentioned above in constructing the questionnaire, it was wrongly assumed that a person who "never" got 
drunk, ipso facto, had no hangover signs. Second, including Sobers in the sample artificially elevated hangover sign correlations. For example, in a prior article [5], an angry mood when drunk was correlated 0.59 for women $(N=646)$ to an index of hangover signs. When Sobers were removed, the magnitude fell to 0.26 $(N=520)$. This sharp reduction was caused by Sober women having " 0 " scores on hangover signs, spuriously yielding a high linear correlation. After removing non-drinkers and Sobers, "non-sober, current drinkers" form the basis of this present analysis $(N=1104)$. Characteristics of this sample compared to the Sobers are presented in the Results section.

\section{Measures of alcohol use}

All the respondents who drank alcohol answered 13 items from Cahalan et al. [10] about their drinking habits. This scale allows calculation of subjects' average weekly ethanol intake according to procedures developed by Jessor [11] and modified slightly by DiFranceisco et al. [12].

To derive the total ounces of ethanol per week for each subject, the individual's reported alcohol intake from beer, wine and liquor is summed. The amount of ethanol for each component beverage is the product of the number of occasions per week that the person drinks the beverage, the number of drinks per occasion, and the average ethanol content (constant) for that beverage. One ounce of ethanol equals approximately two typical drinks of any alcoholic beverage [13]. The sample resided in a town of about 10,000 population in a rural area of Michigan and represented the community in being white, of Anglo-Saxon heritage, $82 \%$ married, and mostly high school educated. Other analyses using this sample show that the drinking behaviors in this small town are similar in relation to various sociodemographic markers described in state and national surveys [14].

\section{Construction of Tecumseh norms}

Once a measure of "oz per week" was constructed for the sample, we then followed a method for constructing a 7-category scale of alcohol use detailed elsewhere [15]. These 7 categories which describe Tecumseh drinking norms were: low very light; high very light; low light; high light; low moderate; high moderate; and heavy. A normalized continuous variable of ethanol and these categories were strongly correlated: for men, $r=0.93 ; p<0.0001$; and for women, $r=0.93 ; p<0.0001$. We preferred using the Tecumseh Norm categories scale to remove the effects of high scoring outliers present in any continuous measure of alcohol consumption. Scores from this scale will be called "alcohol level"in this study.

\section{Psychosocial factors}

1. Neuroticism. This is an additive index from a factor analysis of Eysenck's Neuroticism Scale [16]. There are 24 items, e.g. "Are you moody?", "Do you suffer from nervousness?" Responses were Yes or No. The final score is additive for the Yes responses.

2. Guilt about drinking. A single item taken from the SMAST (Short Michigan Alcoholism Screening Test) [17]: "Do you ever feel guilty about your drinking?" Responses were Yes or No.

3. Reason for drinking. All subjects were asked 12 items describing their reasons for drinking which were then factor-analyzed to construct index items. Reason: Escape has 5 items, e.g. "I drink to forget everything"; "I drink to forget my worries." Responses were [i] not at all true, [ii] slightly true, [iii] fairly true, [iv] very true of me. The total score simply adds these response values.

4. Negative life events. A set of 12 items taken from Holmes and Masuda [18], describing negative life events "in the past 12 months," e.g. death of spouse, family member; separation or divorce; laid-off or fired. Responses were Yes or No. Final scores are the number of Yes responses.

5. Depressed when drunk. Fifteen items asked subjects about what the generally feel when tipsy/drunk. Responses are scored from [i] not at all true, [ii] slightly true, [iii] fairly true, [iv] very true of me. A factor analysis identified 6 items as related to a depressed mood when drunk. These terms included "feel sad, depressed," uninterested in sex," "feel not wanted." The final score is additive.

6. Angry when drunk. This second factor derived from the above 15 items. This scale of 3 items includes: "feel mean, hostile," "feel angry, irritable," "get into arguments," while inebriated. Again, the final score is additive.

Several other variables were also studied: Age was computed from birth date. This variable was reversed, ordering it from older to younger simply to allow positive correlations with alcohol use and hangover signs.

A body mass index was also constructed from 
a formula based on weight $/$ height $^{2}$. This variable was reversed as well, reading from heavier to leaner.

Early (relative) age tipsy. A single item asked "How old were you when you first took a few too many drinks, and got tipsy, high or drunk?" Responses are "Never drank that much" or the age this occurred. We then computed the community sample median age for this item for men (16 years) and for women (17 years) and assigned a " 0 " if at or above the median and " 1 " if below the median (earlier age relative to the community norm).

Hangover signs. Respondents were asked to answer Yes or No to having experienced each of 8 hangover signs after "the last time you had more to drink than intended or got drunk." These signs were: "headache or hangover," "loss of appetite," "diarrhea," "stomach pains," "anxiety," "blackout or loss of memory," "tremors or hand shaking," and "thoughts of suicide." Percents by age, sex, and alcohol level for each sign are reported elsewhere and were ranked by percentage order to indicate mild to severe signs [5]. These 8 signs were then arranged into a 6-point scale according to severity of hangover as follows. This constitutes the Hangover Sign Index (HSI).

1. No signs: gets drunk, but reports no hangover signs.

2. Weak: any or all of these three symptoms: headache, diarrhea, or loss of appetite.

3. Mild: anxiety and/or stomach pains.

4. Strong: any one of blackout, tremor, or thoughts of suicide.

5. Very strong: anxiety plus any one of blackout, tremor, thoughts of suicide.

6. Severe: two or more of blackout, tremor, or suicide thoughts.

The HSI was correlated (in this new sample which excluded Sobers) to a simple index of number of hangover signs, obtained by taking a frequency count of "yes" responses. Computing this correlation for men resulted in $r=0.82$; for women, $r=0.84$; both significant at the $p<0.0001$ level.

\section{Statistical analyses}

A forward stepwise multiple regression analysis with an entry significance threshold of 0.05 was used to test the major hypothesis; age, weight, and alcohol (oz/wk) were included in the original input variables. For separate analyses of interaction effects, age and alcohol were cntcred as main effects with cach psychosocial variable. All analyses were stratified by sex due to the known differences in intake levels (men drink more [5]) and in the physiology of absorption of alcohol (women retain more alcohol in the blood stream than men [19]).

\section{RESULTS}

As mentioned previously, $6 \%$ of the men and $20 \%$ of the women among all drinkers made up the Sober group who claimed "never" getting drunk while drinking. Since this is a group of special interest, we studied further characteristics of these Sober drinkers compared to other drinkers. Bivariate tables and analyses of variance showed that for both genders in this group (data not shown), Sobers were significantly older, drank less, attended church more often, were more often married with less divorce/separation, and for women only, weighed more than their counterparts. Sober men were significantly less likely to be "sensation-seekers" or to drink to escape than other male drinkers. Sober women had significantly lower mean scores for sensation-seeking, guilt about drinking, drink to escape and negative life events than other drinking women.

Table 1 indicates that there are no significant sex differences in HSI among the non-sober

Table 1. HSI categories by sex (excluding sober drinkers)

\begin{tabular}{lrrrrrr}
\hline \multirow{2}{*}{ HSI categories } & \multicolumn{2}{c}{ Total } & \multicolumn{2}{c}{ Male } & \multicolumn{2}{c}{ Female } \\
& $\%$ & $(N)$ & $\%$ & $(N)$ & $\%$ & $(N)$ \\
\hline 1. No signs & 23 & $(256)$ & 23 & $(134)$ & 23 & $(122)$ \\
2. Weak & 47 & $(515)$ & 46 & $(270)$ & 47 & $(245)$ \\
3. Mild & 17 & $(185)$ & 16 & $(91)$ & 18 & $(94)$ \\
4. Strong & 7 & $(81)$ & 8 & $(45)$ & 7 & $(36)$ \\
5. Very strong & 4 & $(49)$ & 5 & $(31)$ & 4 & $(18)$ \\
6. Severe & 2 & $(18)$ & 2 & $(13)$ & 1 & $(5)$ \\
\hline Total $N$ & $100 \%$ & $(1104)$ & $100 \%$ & $(584)$ & $100 \%$ & $(520)$ \\
\hline
\end{tabular}

Chi-square $=6.1, d f=5$, N.S.

Tau-B $=0.02$, N.S. 
Table 2. Percent "yes" to five major reasons for drinking* by sex

\begin{tabular}{|c|c|c|c|c|c|c|c|c|c|c|}
\hline \multirow{3}{*}{$\begin{array}{l}\text { Reasons } \\
\text { for } \\
\text { drinking }\end{array}$} & \multirow{2}{*}{\multicolumn{2}{|c|}{ Totals }} & \multirow{2}{*}{\multicolumn{2}{|c|}{ Sobers }} & \multicolumn{6}{|c|}{ Hangover severity ${ }^{\dagger}$} \\
\hline & & & & & \multicolumn{2}{|c|}{$\begin{array}{l}\text { No } \\
\text { signs }\end{array}$} & \multicolumn{2}{|c|}{$\begin{array}{l}\text { Weak/ } \\
\text { mild }\end{array}$} & \multicolumn{2}{|c|}{$\begin{array}{l}\text { Strong to } \\
\text { severe }\end{array}$} \\
\hline & $\begin{array}{c}\mathrm{M} \\
(620)\end{array}$ & $\underset{(646)}{F}$ & $\begin{array}{c}M \\
(36)\end{array}$ & $\begin{array}{c}F \\
(126)\end{array}$ & $\begin{array}{c}\mathbf{M} \\
(134)\end{array}$ & $\underset{(122)}{\mathbf{F}}$ & $\underset{(361)}{M}$ & $\underset{(339)}{F}$ & $\begin{array}{c}M \\
(89)\end{array}$ & $\begin{array}{c}F \\
(59)\end{array}$ \\
\hline \multicolumn{11}{|l|}{ Conform } \\
\hline 1. Be sociable & 65 & 67 & 56 & 55 & 61 & 71 & 67 & 70 & 71 & 64 \\
\hline 2. Others drink $\$$ & 46 & 50 & 42 & 34 & 37 & 51 & 47 & 54 & 57 & 56 \\
\hline \multicolumn{11}{|l|}{ Release } \\
\hline 3. Like taste & 65 & 51 & 33 & 35 & 60 & 49 & 67 & 57 & 78 & 61 \\
\hline 4. Enjoy it & 70 & 50 & 39 & 22 & 64 & 53 & 72 & 58 & 84 & 56 \\
\hline 5. To relax & 50 & 37 & 14 & 15 & 49 & 41 & 49 & 40 & 69 & 53 \\
\hline
\end{tabular}

drinkers. Furthermore chi-square analyses by sex for each of the 8 hangover signs again revealed no significant differences for 7 of 8 hangover signs. The one difference was that men reported significantly more blackouts $(7 \%)$ than women (4\%). Analysis by age and sex (data not shown) revealed that older men $(50+$ years $)$ compared to older women report a higher proportion experiencing each of 8 signs after being drunk (although $N \mathrm{~s}$ are small, especially for women). Younger (18-30) women, conversely, showed significantly higher proportions than younger men of weak or mild signs: headache (60 vs $40 \%, N=100$ of both genders reporting this sign), loss of appetite ( 68 vs $32 \%, N=90$ ), diarrhea (57 vs $43 \%, N=117)$ and stomach pains ( 61 vs $39 \%, N=59$ ), but did not differ on anxiety ( 50 vs $50 \%, N=46$ ) or for the 3 most severe signs (blackout, tremor, or suicide thoughts).

Table 1 also shows that about $23 \%$ of all current drinkers reported no hangover signs when drunk, with no difference between men and women. This lack of difference in percent no signs remained when analyzed by age-sex groups. Analysis comparing those with no signs, those with weak/mild and those with strong to severe signs shows that for both genders (data not shown) the no signs group were significantly less neurotic and drank less (more very light drinkers and less heavy) than those with weak/mild signs, but did not differ on drinking daily, or relative age first drunk. This seems in line with a report by Pristach et al. [20] that 23\% of their alcoholic patient sample (male and female) never experienced hangover signs. Those with strong to severe signs had signifi- cantly different proportions or means than the no signs or weak/mild sign groups for the following variables: less often married and more often divorced/separated, least in church attendance, highest scores on each of the 6 psychosocial measures, drank more (most heavy least light drinkers, most daily drinkers, and most relative early age when first drunk) for both men and women.

Table 2 further analyses these four hangover groups by their reasons for drinking, selected and rank-ordered as explained in the table footnote. Percents in the totals column tell us that for these social drinkers, two-thirds of the men drink because they enjoy it, like the taste, and to be sociable; for women, the major reasons are to be sociable, but only half then agree with the men that they like the taste and enjoy it, and because the people they are with are drinking. For those with hangover signs, the increase in percent of each reason increases for men with severity of signs. Indeed this monotonic effect holds for all 12 reasons reported (data not shown) and appears to mean that those men experiencing hangovers drink for all the reasons and must therefore be psychically loaded with expectations of what alcohol will do for them before and during drinking.

In contrast, Sobers have different expectations about alcohol. They drink mostly for reasons of conformity and do not drink for release, as do the non-Sobers. Indeed only about $2 \%$ of both male and female Sobers reported drinking to "cheer up when in a bad mood" compared to those with strong to severe signs where $42 \%$ of men and $29 \%$ of women agreed with this reason. The majority of Sobers as seen 
in Table 2 also do not "enjoy" drinking as do the non-Sobers, regardless of gender.

We next ran Pearson correlations of 9 major variables (used in subsequent multivariate analyses) predicting to the HSI. First, the correlation of alcohol use to HSI is low for men, $r=0.23, r^{2}=5 \%$ and lower for women, $r=0.15, r^{2}=2 \%$. For men and women, there is a negligible relation of both age and body mass to HSI. For both men and women, however, neuroticism, guilt about drinking, drinking to escape, negative life events, and negative moods when drunk (depression and anger) are significantly related to HSI. All these psychosocial variables are positively intercorrelated $(0.10-0.30)$. For both sexes, higher consumption of alcohol is most strongly correlated with drinking to escape (males, $r=0.52$; females, $r=0.44$ ) and less strongly correlated with guilt about drinking $(0.30,0.27)$, angry when drunk $(0.27,0.18)$, and weakly, with early (relative) age when first tipsy or drunk $(0.17,0.17)$. Patently, alcohol use is significantly related to the psychosocial variables.

To observe independent effects of each variable in predicting HSI, the 9 major predictor variables mentioned above were run in a stepwise multiple regression analysis. Results are shown in Table 3. All of the variables except weight and drinking to escape appear as independent and additive predictors to the HSI. For both men and women, guilt about drinking, neuroticism, angry mood when drunk, and negative life events are each significantly related to HSI. For men, amount of alcohol and being depressed when drunk also enter into the set of predictors. For women, being younger and reporting an earlier (relative) age when first tipsy/drunk complete the predictive variables. Thus, the simple correlation between amount of alcohol and HSI for men, $r=0.23 ; r^{2}=5 \%$, is significantly increased $(p<0.05)$ to $R=0.43$,
$R^{2}=19 \%$ by the addition of alcohol-related psychosocial variables. For women, the simple alcohol and HSI correlation of $r=0.15$, $r^{2}=2 \%$ is also significantly increased $(p<0.05)$ to $R=0.46, R^{2}=21 \%$.

The finding among women that alcohol consumed is not included in the final set of significant predictors might be "explained" by (1) the low amount of variance contributed by alcohol level, and (2) the fact that the alcohol-related psychosocial variables of guilt about drinking, angry mood when drunk, reason: escape and early (relative) age when first drunk are all behaviors which include the actual consumption of alcohol and are not independent of alcohol use. Trial regressions using these main effects and interaction terms with alcohol did not change the $R^{2}$ and did not clarify the results, nor did the addition of a variable measuring maximum or "binge" drinking. Nor was any relation found between number of years drinking and hangover, for either gender.

Nevertheless, it seems valid that alcohol would contribute to hangover signs, if not independently, then through interaction with negative psychosocial variables. Therefore, we next explored interaction between alcohol level and each psychosocial variable with results shown in Table 4. We used a regression model with 7 variables which were run separately for each psychosocial variable (PSV). For both genders, alcohol level, because of its small variance, is "squeezed out" of all results as a main effect. However, for men, all 6 tests showed an interaction of alcohol level and the specific psychosocial factor. Results are clear that the interaction effect for males between alcohol level and each psychosocial variable is stronger than for the main effect of each variable alone. For women, 4 of 6 interaction effects were significant, and consistent main effects were: being younger and first getting drunk at an early (relative) age. It

Table 3. Stepwise multiple regression of six psychosocial variables, age, weight and alcohol level on the hangover sign index, by sex

\begin{tabular}{|c|c|c|c|c|c|}
\hline \multicolumn{3}{|c|}{ Males $(N=584)$} & \multicolumn{3}{|c|}{ Females $(N=520)$} \\
\hline Variables & $R$ & $R^{2}$ & Variables & $R$ & $R^{2}$ \\
\hline Guilt about drinking & 0.30 & 0.09 & Guilt about drinking & 0.33 & 0.11 \\
\hline Neuroticism & 0.21 & 0.13 & Neuroticism & 0.21 & 0.15 \\
\hline Angry when drunk & 0.17 & 0.16 & Angry when drunk & 0.16 & 0.17 \\
\hline Depressed when drunk & 0.10 & 0.17 & Age (younger) & 0.15 & 0.19 \\
\hline Negative life events & 0.09 & 0.19 & Rel. early age tipsy & 0.11 & 0.20 \\
\hline Alcohol level & 0.07 & 0.19 & Negative life events & 0.09 & 0.21 \\
\hline Totals & 0.43 & $0.19^{*}$ & & 0.46 & $0.21^{*}$ \\
\hline
\end{tabular}


Table 4. Beta coefficients, $R$ and $R^{2}$ for multiple regression of four main effects and three interaction terms on HSI for each of 6 psychosocial variables, by sex (males: $N=584$; females: $N=520$ )

\begin{tabular}{|c|c|c|c|c|c|c|c|c|c|}
\hline \multirow[b]{2}{*}{$\begin{array}{l}\text { Psychosocial } \\
\text { variable } \\
\text { (PSV) }\end{array}$} & \multicolumn{4}{|c|}{ Main effects } & \multicolumn{5}{|c|}{ Interaction terms } \\
\hline & PSV & $\begin{array}{l}\text { Alc. } \\
\text { level }\end{array}$ & $\begin{array}{c}\text { Age } \\
\text { (reverse) }\end{array}$ & $\begin{array}{c}\text { Early } \\
\text { (rel.) } \\
\text { Age } \\
\text { tipsy }\end{array}$ & $\begin{array}{l}\text { Alc. } \times \\
\text { PSV }\end{array}$ & $\begin{array}{c}\text { Alc. } \times \\
\text { age (rev.) }\end{array}$ & $\begin{array}{c}\text { Alc. } \times \text { early } \\
\text { (rel.) } \\
\text { age } \\
\text { tipsy }\end{array}$ & $R^{*}$ & $R^{2}$ \\
\hline \multicolumn{10}{|l|}{ Neuroticism } \\
\hline M & 0.18 & - & - & - & 0.28 & - & - & 0.32 & 0.10 \\
\hline$F$ & 0.23 & - & - & 0.11 & - & 0.20 & - & 0.32 & 0.10 \\
\hline \multicolumn{10}{|l|}{$\begin{array}{l}\text { Guilt about } \\
\text { drinking }\end{array}$} \\
\hline $\mathbf{M}$ & 0.11 & - & - & - & 0.32 & - & - & 0.33 & 0.11 \\
\hline $\mathbf{F}$ & 0.33 & - & 0.17 & 0.13 & - & 一 & - & 0.39 & 0.15 \\
\hline \multicolumn{10}{|l|}{$\begin{array}{l}\text { Reason: } \\
\text { escape }\end{array}$} \\
\hline$M$ & 0.07 & - & - & - & 0.29 & - & - & 0.30 & 0.09 \\
\hline $\mathbf{F}$ & - & - & 0.16 & 0.11 & 0.20 & - & - & 0.29 & 0.08 \\
\hline \multicolumn{10}{|l|}{$\begin{array}{l}\text { Depressed } \\
\text { when drunk }\end{array}$} \\
\hline M & 0.11 & - & - & - & 0.31 & - & - & 0.34 & 0.11 \\
\hline $\mathbf{F}$ & 0.11 & - & 0.18 & 0.12 & 0.21 & - & - & 0.31 & 0.10 \\
\hline \multicolumn{10}{|l|}{$\begin{array}{l}\text { Angry } \\
\text { when drunk }\end{array}$} \\
\hline $\mathbf{M}$ & - & - & - & - & 0.31 & - & - & 0.31 & 0.09 \\
\hline $\mathrm{F}$ & - & - & 0.23 & 0.12 & 0.26 & -0.17 & - & 0.35 & 0.12 \\
\hline \multicolumn{10}{|l|}{$\begin{array}{l}\text { Negative } \\
\text { life events }\end{array}$} \\
\hline M & - & 0.08 & - & - & 0.26 & - & - & 0.27 & 0.07 \\
\hline$F$ & - & - & 0.14 & 0.13 & 0.21 & - & - & 0.28 & 0.08 \\
\hline
\end{tabular}

*All $R: p<0.001$.

must be noted that for women only, neuroticism and guilt about drinking emerged as main effects.

We chose to further describe in more detail how alcohol level and the psychosocial variables combine to predict severity of hangover signs. Using "angry when drunk" as an example,
Table 5 shows that for both men and women, at each level of alcohol use those with no signs appear to have a consistently greater percent with low anger when drunk than high anger. For those with hangovers among the high volume drinkers, subjects with mild/weak signs show a greater percent difference between low

Table 5. Percent of hangover severity by sex, alcohol level and mood anger when

\begin{tabular}{|c|c|c|c|c|c|c|}
\hline \multirow{2}{*}{$\begin{array}{l}\text { Alcohol level*: } \\
\text { Angry when drunk } \uparrow:\end{array}$} & \multicolumn{2}{|c|}{ Low } & \multicolumn{2}{|c|}{ Medium } & \multicolumn{2}{|c|}{ High } \\
\hline & Low & High & Low & High & Low & High \\
\hline Hangover Index & \multicolumn{6}{|c|}{ Males $(N=584)$} \\
\hline No signs & 31 & 20 & 25 & 12 & 22 & 13 \\
\hline Mild/weak & 48 & 48 & 49 & 45 & 53 & 31 \\
\hline Strong & 15 & 16 & 14 & 21 & 6 & 26 \\
\hline Very strong to severe & 6 & 16 & 12 & 22 & 19 & 30 \\
\hline$N=$ & $(177)$ & $(25)$ & $(164)$ & $(67)$ & (73) & $(78)$ \\
\hline & \multicolumn{6}{|c|}{ Females $(N=520)$} \\
\hline No signs & 31 & 12 & 21 & 16 & 24 & 7 \\
\hline Mild/weak & 46 & 36 & 50 & 50 & 52 & 30 \\
\hline Strong & 15 & 24 & 21 & 24 & 8 & 22 \\
\hline Very strong to severe & 8 & 18 & 8 & 10 & 16 & 41 \\
\hline$N=$ & (213) & (33) & $(171)$ & $(38)$ & (38) & (27) \\
\hline
\end{tabular}

*Low $=<3$ drinks per week; medium $=($ men $) \geqslant 3$ to $<14$, (women) $\geqslant 3$ to $\leqslant 7$; High $=($ men $) \geqslant 2+$ daily, (women) $\geqslant 1+$ daily.

†Low = below median; high = at or above median; within gender. 
and high anger when drunk. At all levels of alcohol use, those with very strong to severe signs show greater proportions reporting high anger than low anger when drunk. The pattern emerging from the whole table suggests that the combination of higher alcohol level and high anger when drunk predicts more severe hangover signs. Low alcohol consumption and low anger while drunk are reported by only $6 \%$ of men and $8 \%$ of women having very strong/severe hangover signs. In the same severe sign group, $30 \%$ of the men and $41 \%$ of the women have high alcohol use and high anger; thus under these high volume conditions, women show more very strong hangover signs than men. These effects are most likely strongly weighted by the younger women. These results support a finding that alcohol and angry mood when drunk do interact to predict severity of hangover signs. Similar patterns were also observed for the other 5 psychosocial variables, for both genders, except for depressed mood when drunk in women where only alcohol level, not interacting with depressed mood, appears to produce more strong signs in this simple frequency test.

\section{DISCUSSION}

This study strongly underlines the importance of psychosocial factors in producing hangover symptoms in drinkers. Guilt about drinking, a decidedly neurotic outlook toward life (as defined by Eysenck's [16] Scale, which includes general guilt and anxiety), succumbing to angry moods or being led into depressed states while tipsy or high, as well as having recently suffered through significant negative life events and having multiple reasons for drinking all may add to the potential for having hangover symptoms after drinking. These factors appear more important than the amount of alcohol consumed as tested by multiple regression technique. However, average amount of alcohol consumed clearly contributes to the variance of hangover signs through interaction with psychosocial factors, across the spectrum of social drinkers.

In this study, the patterns of interaction predicting to hangover signs differed between men and women. For men, all negative affect variables interacted with alcohol level in separate multiple regression tests (with age and weight) for each psychosocial variable and in bivariate tests. For women, certain main effects were stronger than interaction ones: namely, neuroti- cism, guilt about drinking, being younger, and first getting drunk at an age earlier than community norms. For women 4 other psychosocial variables showed only interaction effects with alcohol: namely, drinking to escape, being angry and/or depressed when drunk, and more negative life events in the past year. Clearly these results for women are more complex than for men.

That some of the variance in predicting hangovers in women is attributed to being younger and reporting an earlier relative age when first tipsy is not easily understood and would require further research. These effects persist regardless of weight, though younger women carry less weight than their elders, and would be more vulnerable to getting "high." This vulnerability is partly based on biological and genetic differences between men and women. Since women are generally lighter in weight than men, have a higher proportion of body fat, and have a smaller proportion of fluid relative to their total weight than men, alcohol is absorbed faster by women [19]. Alcohol is not rapidly absorbed by fat and thus tends to remain at high levels in the blood stream. Also, owing to the smaller amount of fluid, alcohol remains less diluted. Consequently, women generally need less alcohol to feel high or drunk. In fact, drinking norms and consumption for men and women almost always differ within communities and in the nation [21]. In Tecumseh also, men drank more than women (and the generation of adults in 1977 consumed more than did their parents and other adults in 1960) [15]. A comparison of the raw ethanol consumption of both parents and offspring in our sample reiterated these observations. Cultural "permission" to drink more for younger women would most likely lead to more hangovers, most especially for those who are "uptight" before and during consumption.

Younger women (18-30) in our sample also reported significantly higher proportions of weaker hangover signs than men (headache, loss of appetite, diarrhea) and a stronger sign, stomach pains, at all levels of alcohol use, even though the women drank much less than the men. For those teenage girls who were drunk at an earlier age relative to their peers in the community, the data show that as young women they also suffer more from hangover signs. Such a subset would not be categorized as "very sensible" drinkers, and many of them might also be "problem" drinkers [22]. Psycho- 
logically, they would be expected to be more neurotic, guilty about drinking, sad or angry when drunk, and experience more negative life events. They would have multiple expectations about how using alcohol might benefit them. Strong hangover signs for young women might be an early risk factor predicting to early midlife crisis with alcohol use as part of the maladjustment and unhappiness.

All of the psychosocial alcohol-related measures used in this study could reflect a chronic condition of "negative affect" [23] whereby, in essence, life is not able to be enjoyed and alcohol is used to alleviate the chronic psychic pain of this underlying state. The interaction of this emotionality with alcohol then induces hangover signs. As Chafetz [3] suggests, when we are "tense and uptight while taking alcohol, we're more predisposed to hangover." There is a dearth of research on this hypothesis as most experimental studies are exclusively focused on the effects of alcohol dosage (e.g. [24]). Further the subset of drinkers whose emotionality interacts with alcohol use to induce "strong" hangover signs might be a small minority of drinkers. It must be recalled that over half the social drinkers in this sample fell into categories of (a) being Sober or (b) have no hangover signs or (c) have very mild hangover, especially for the women, who tended to be light drinkers. Further, Gunn [4], Pristach et al. [20] and Smith and Barnes [25] report that even among alcoholics, almost half do not report hangover signs.

It must be noted that any measure of hangover signs reasonably includes psychological effects ascertained by subjective responses. Attempts to define hangover symptoms in only biological terms and measures have not been notably successful [25]. The hangover scale in this research (HSI) includes two clearly psychological events, namely, "anxiety" and "suicide thoughts." Is there a confounding when, e.g. neuroticism or guilt is correlated to the HSI? First, only three people reported "suicide thoughts," so this could hardly affect the results. Second, we removed "anxiety" from the scale, and obtained the same significant results. Also while younger women exhibited significantly more hangover signs of a "physical" focus than men (headache, loss of appetite, diarrhea, and stomach pains), the proportion in the total sample reporting "anxiety" as a hangover sign did not differ between the sexes, as might be expected in that women had higher "neuroticism" scores than men.

It should also be noted here that certain variables in this research, i.e. anger or depression when drunk, are "face valid" survey items; other variables, i.e. Eysenck's Neuroticism, are widely used standard measures. The former suffer from lack of testing for validity and reliability, while the scores for the latter measures are generalized indicators of complex concepts, which confound specific processes, e.g. fear or anxiety specifically about drinking.

Further, this is a correlational study, and it is interesting to observe that psychosocial factors, alcohol, and hangover appear to cluster; however, the design and measures of this study prohibit a causal interpretation. One can, however, conjecture about the clinical processes involved. We can assume that emotional pain resulting from negative psychosocial factors can either inhibit or facilitate drinking to hangover, as for example, in psychosocial systems, where a range of variation for a trait is controlled by feedback (inhibiting when excessive or facilitating when depleted). For the Sobers, there is a continuous monitoring such that they do not reach the intoxication stage and therefore avoid hangovers. For many light drinkers, who occasionally get intoxicated, the hangover itself may act to inhibit such subsequent drinking occasions. For social drinkers, certain "positive" life events (e.g. marriage, having children, taking a permanent job) may interact with the hangover experiences and result not only to diminish one's level of drinking, but even to become Sober or stop drinking altogether. Smith and Barnes [25] first suggested that hangover signs may serve to inhibit drinking or promote a decrease to light levels of intake, and in a later study [6] did indeed find such an effect. For those heavy drinkers who do not experience hangovers, drinking may bring temporary relief from psychic pain and therefore they continue to drink; for those heavy drinkers who do experience severe hangovers, their conduct while intoxicated may precipitate more negative life events, and increase guilt, which then precipitates further intoxications. Future research should be designed to investigate simultaneously the psychosocial and physiological conditions which are involved in these processes. To date, there is practically no research which examines these issues among normal or social drinkers. Such knowledge would have import for public health educational efforts 
toward regulating alcohol use as well as for preventive family medicine.

Future research might also include more specific measures of conflicts about drinking, in ordcr to increase the predictability of hangovers from psychosocial sources. Such conflicts may be generated by: parental strictures, discipline, and punishment for early and adult drinking; parental and individual early and current values about use of alcohol; moral evaluations by spouses/lovers toward the individual's use of alcohol; perception of relatives' and friends' attitudes towards the individual's alcohol use; the social context of drinking and getting drunk (secret drinking; at parties or bars, etc.); being in negative "love" relations (breakups, divorce) when drinking is for "escape" from conflict. All of these factors which induce "being uptight" when consuming alcohol we assume will contribute more variance in predicting hangovers. Conversely, all factors which increase the behaviors describing "sensible" drinking [26] should inhibit the severity of hangover experience and consequences.

\section{REFERENCES}

1. Lolli G. The hang-over in relation to the theory and treatment of alcohol addiction. Q J Stud Alcohol 1946; 7: 193-213.

2. Karpman B. The Hangover; a Critical Study of the Psychodynamies of Alcoholism. Springfield, IL: Thomas; 1957.

3. Chafetz ME. Why Drinking Can Be Good for You. New York: Stein \& Day; 1976.

4. Gunn RC. Hangovers and attitudes toward drinking. Q J Stud Alcohol 1973; 34: 194-198.

5. Harburg E et al. Negative affect, alcohol consumption and hangover symptoms among normal drinkers in a small community. J Stud Alcohol 1981; 42: 998-1012.

6. Smith CM. Symptoms of intoxication and hangovers perceived to modify subsequent alcoholic beverage consumption. Abstract presented to the Committee on Problems of Drug Dependence, Philadelphia; 14-19 June 1987.

7. Napier JA et al. The Tecumseh Community Health Study. In Kessler LL, Level ML, Eds. Casebook of Community Studies. Baltimore, MD: Johns Hopkins Press; 1970: 25-46.
8. Harburg E et al. Heredity, stress, and blood pressure, a family set method: I. J Chron Dis 1977; 30: 625-647.

9. Moll $\mathbf{P}$ et al. Heredity, stress and blood pressure, a family set approach: the Detroit Project revisited. J Chron Dis 1983; 36: 317-328.

10. Cahalan et al. American Drinking Practices. New Brunswick, NJ: Rutgers Center of Alcohol Studies; 1969.

11. Jessor R. Society, Personality and Deviant Behavior. Huntington, NY: Krieger Publishing Co.; 1968.

12. Difranceisco $\mathrm{W}$ et al. Tecumseh Family Health Project: Methods Notes on the Calculation of Ethanol Intake Variables for 1960 and 1977 Samples. Tecumseh Family Health Project. Ann Arbor: The University of Michigan; 6 October 1986; Report No.3.

13. Gleiberman L, Harburg E. Alcohol usage and blood pressure: a review. Hum Biol 1986; 58: 1-31.

14. O'Connell B. Early Family Behavior, Gender Differences and Alcohol Usage in Persons Raised in a Small Community. Unpublished Doctoral Dissertation. Ann Arbor, MI: The University of Michigan; 1980.

15. Harburg $E$ et al. Community norms of alcohol usage and blood pressure: Tecumseh, Michigan. Am J Public Health 1980; 70: 813-820.

16. Eysenck HJ, Eysenck SBG. Manual: Eysenck Personality Inventory. San Diego, CA: Educational and Industrial Testing Service; 1968.

17. Selzer ML et al. A self-administered short Michigan Alcoholism Screening Test (SMAST). J Stud Alcohol 1975; 36: 117-126.

18. Holmes $\mathbf{T H}$, Masuda $\mathbf{M}$. Life change and illness susceptibility. In: Dohrenwend BS, Dohrenwend BP Eds. Stressful Life Events: Their Nature and Effects. New York: John Wiley; 1974.

19. Mendelson JH, Mello NK. Alcohol Use and Abuse in America. Boston, MA: Little, Brown and Co.; 1985.

20. Pristach $\mathrm{C}$ et al. Alcohol withdrawal syndromes-prediction from detailed medical and drinking histories. Drug Alcohol Depend 1983; 11: 177-199.

21. Klatsky AL et al. Racial patlerns of alcoholic beverage use. Alcoholism: Clin Exp Res 1983; 7: 372.

22. Harburg E et al. Beyond Problem Drinking: Towards a Concept and Measure of a Sensible/Problem Drinking Scale for Social Drinkers. Program for Urban Health Research. The University of Michigan; 1989: Report No. 25.

23. Watson D, Clark LA. Negative affectivity: the disposition to experience aversive emotional states. Psychol Bull 1984; 96: 465-490.

24. Chapman LF. Experimental induction of hangover. $\mathbf{Q}$ J Stud Alcohol 1970; 5(Suppl.): 67-86.

25. Smith CM, Barnes GM. Signs and symptoms of hangover: prevalence and relationship to alcohol use in a general adult population. Drug Alcohol Depend 1983; 11: 249-269.

26. Harburg E, Gleiberman L. A Sensible Approach to Alcohol as a Public Health Goal. Program for Urban Health Research. The University of Michigan; 1992: Report No. 30. 